\title{
Snow particle characteristics in the saltation layer
}

\section{Christof GROMKE, ${ }^{1,2 *}$ Stefan HORENDER, ${ }^{1}$ Benjamin WALTER, ${ }^{1,3}$ Michael LEHNING ${ }^{1,4}$}

\author{
${ }^{1}$ WSL Institute for Snow and Avalanche Research SLF, Davos Dorf, Switzerland \\ E-mail: c.b.gromke@tue.nl \\ ${ }^{2}$ Building Physics and Services, Eindhoven University of Technology, Eindhoven, The Netherlands \\ ${ }^{3}$ Physikalisch-Meteorologisches Observatorium Davos (PMOD), Davos Dorf, Switzerland \\ ${ }^{4}$ CRYOS, School of Architecture, Civil and Environmental Engineering, École Polytechnique Fédérale de Lausanne,
} Lausanne, Switzerland

\begin{abstract}
Shadowgraphy was employed to study snow saltation in boundary-layer wind tunnel experiments with fresh, naturally deposited snow. The shadowgraphy method allowed for a temporally and spatially high-resolution investigation of snow particle characteristics within a measurement area of up to $50 \mathrm{~mm} \times 50 \mathrm{~mm}$. Snow particle size and number characteristics, and their variation with height in the saltation layer, were analysed. The following observations and findings were made for the saltation layer: (1) the particle number decreases exponentially with height, (2) the mean particle diameter is fairly constant, with a very slight tendency to decrease with height, (3) the maximum particle diameter decreases linearly with height, and (4) the snow particle size distribution can be adequately described by gamma probability density functions. The shape and scale parameters of the gamma distribution were found to vary systematically, though only slightly, with height over ground and between experiments with different snowpack characteristics.
\end{abstract}

KEYWORDS: snow, wind-blown snow

\section{INTRODUCTION}

Saltation is an important transport mechanism in drifting snow and is considered to accomplish the bulk of snow mass transport (e.g. Kind, 1990). It is generally estimated that 50$75 \%$ of the total mass transport of snow is accomplished by saltation. Typical transport rates range from 0.001 to $0.03 \mathrm{~kg} \mathrm{~m}^{-1} \mathrm{~s}^{-1}$, with mass concentrations between 0.1 and $1 \mathrm{~kg} \mathrm{~m}^{-3}$ (Takeuchi, 1980; Pomeroy and Gray, 1990; Gauer, 2001). The fraction of saltation of the total snow mass transport depends on the wind shear velocity at the surface and on the wind speed above ground. For low and medium wind speeds, it accounts for the majority of the total transported snow mass. Liston and Sturm (1998) estimate that for shear velocities below $\sim 0.45 \mathrm{~m} \mathrm{~s}^{-1}$ the transport of snow by saltation is larger than that by turbulent suspension. Apart from its relative importance in the total snow mass transport and more fundamentally, saltation constitutes a lower boundary condition for drifting snow when saltating particles are entrained by turbulent eddies and enter into suspension (e.g. Radok, 1968; Pomeroy, 1989; Xiao and others 2000). For this reason, insights into particle dynamics and characteristics in the saltation layer play an important role for the understanding and modelling of the snow transport in turbulent suspension.

The thickness of the saltation layer depends on the shear velocity at the surface (e.g. Greeley and Iversen, 1985) and is typically $<50$ to $100 \mathrm{~mm}$. Since this is rather large or small compared to the dimensions and detection resolution of measurement devices usually employed in studies of drifting snow (e.g. Snow Particle Counter SPC (Sato and others, 1993), compartment traps (e.g. Schmidt, 1986) or the FlowCapt sensor (Chritin and others, 1999)), a detailed height-resolved analysis of the saltation layer structure is

*Institute for Hydromechanics, Karlsruhe Institute of Technology KIT, Karlsruhe, Germany. difficult or even impossible to obtain. A detailed heightresolved analysis requires the application of other measurement techniques such as laser visualization and imageprocessing techniques, as previously employed for the study of aeolian transport of sand and PVC particles (e.g. Dong and others, 2003; Cierco and others, 2008; Creyssels and others, 2009). As a consequence, less knowledge of snow particle characteristics and dynamics (e.g. number or mass concentration, size and velocity, and their variation with height) is available, and as a surrogate, uniform particle characteristics in the saltation layer are commonly assumed. The snowdrift models of Liston and Sturm (1998) and Naaim-Bouvet and others (2010), for example, assume a uniform snow mass concentration profile within the saltation layer. Doorschot and others (2001) and Doorschot and Lehning (2002) operate with a single snow particle size in their snow transport model.

To the best of our knowledge, there exist only a few studies in which the height variation of snow particle size characteristics or dynamics in the saltation layer has been addressed. Sugiura and others (1998) measured particle size distributions and snow mass fluxes at different levels between 16 and $61 \mathrm{~mm}$ above the snow surface for different shear stress velocities in a cryospheric wind tunnel. Their results show an increase in the frequency of smaller particles and an exponential decrease in the snow mass flux with height. Nishimura and Hunt (2000) and Gordon and others (2009) report exponentially decreasing snow mass concentrations for the saltation layer.

In contrast, measurements of particle size characteristics above the saltation layer and within the lower few meters of the atmospheric boundary layer have been undertaken more frequently (e.g. Schmidt, 1982; Schmidt, 1984, 1986; Gordon and Taylor, 2009). Schmidt (1982) measured particle size characteristics of blowing snow at six levels within $1 \mathrm{~m}$ above the ground. He found a decrease in the mean particle diameter with height where the particle size distribution at each height level could adequately be described by gamma 
Table 1. Experiment boundary conditions and measurement parameters

\begin{tabular}{|c|c|c|c|c|c|}
\hline & $U_{\delta}$ & $T_{\text {air }}$ & $\begin{array}{l}\text { Number of } \\
\text { frames }\end{array}$ & $\begin{array}{l}\text { Recording } \\
\text { time }\end{array}$ & $\mathrm{FoV}^{*}$ \\
\hline & $\mathrm{ms}^{-1}$ & ${ }^{\circ} \mathrm{C}$ & & $\mathrm{s}$ & $\mathrm{mm}$ \\
\hline exp. 1a & 10.0 & $-1.4 \pm 0.1$ & 1500 & 30 & $50 \times 50$ \\
\hline exp. 1b & 9.5 & $-1.4 \pm 0.1$ & 3000 & 60 & $50 \times 50$ \\
\hline exp. 2a & 9.0 & $-4.5 \pm 0.2$ & 6000 & 120 & $25 \times 50$ \\
\hline exp. 2b & 10.0 & $-4.5 \pm 0.2$ & 6000 & 120 & $25 \times 50$ \\
\hline
\end{tabular}

*Field of view (horizontal $\times$ vertical).

probability density distributions. Gordon and Taylor (2009) also reported a decrease in the mean snow particle diameter with height and size distributions that can be fitted by gamma probability density distributions.

In this paper, snow particle size characteristics and their variation with height in the saltation layer are analysed. The novelty of this study is the detailed height-resolved analysis which is, to the best of our knowledge, unprecedented. The aim is to contribute to a better understanding and improved modelling of snow transport. The paper is structured as follows: The experimental set-up and the measurement technique are explained in Section 2. The measurement results, i.e. vertical profiles of particle number, particle size characteristics and particle size distribution, are presented and discussed in Section 3, followed by a summary and conclusion in Section 4.

\section{METHODS}

\subsection{Boundary-layer wind tunnel and saltation experiments}

Snowdrift experiments were performed in the boundarylayer wind tunnel of the WSL Institute for Snow and Avalanche Research SLF (Clifton and others, 2006). The wind tunnel is accommodated in a non-heated building at $1650 \mathrm{ma}$ a.s.l. and is an open-circuit suck-down type, operated with fresh outdoor air. It has a total length of $17 \mathrm{~m}$ and consists of an inlet contraction followed by a $6 \mathrm{~m}$ long fetch that can be used for the arrangement of flowconditioning devices and an $8 \mathrm{~m}$ long test section (see Gromke and others, 2011, fig. 1). The ceiling in the flowconditioning part and test section is adjustable to control the stream-wise pressure gradient. The cross section has nominal dimensions of $1 \mathrm{~m} \times 1 \mathrm{~m}$.

For our experiments, an $8 \mathrm{~m}$ long, $1 \mathrm{~m}$ wide snowpack of $0.10-0.15 \mathrm{~m}$ thickness was placed in the test section. The snowpack was assembled by four trays of $2 \mathrm{~m}$ length and $1 \mathrm{~m}$ width. Prior to each experiment, the trays were placed outside the building in a wind-sheltered, sun-shaded area so that, during a snowfall, they were homogeneously filled with naturally deposited snow (see Gromke and others, 2011, fig. 2). The trays were then carefully positioned in the wind tunnel test section. By means of lifting tables in the test section, the snow surface was flush-mounted to the floor level of the upwind flow-conditioning part. This type of setup and procedure has been successfully employed in the past for various boundary-layer flow studies over snow (e.g. Clifton and others, 2006; Clifton and Lehning, 2008; Guala and others, 2008; Gromke and others, 2011).

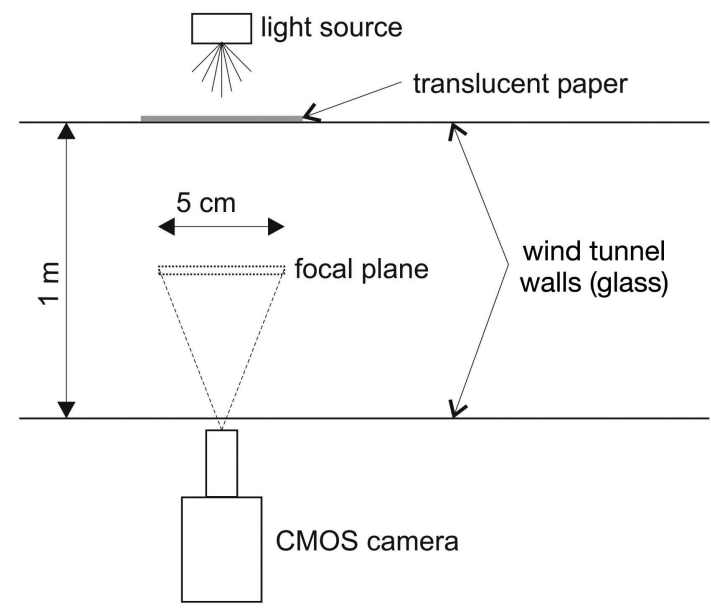

Fig. 1. Measurement technique and set-up in the wind tunnel.

For the present snow transport investigations, no flowconditioning devices (e.g. spires or ground-mounted roughness elements) were employed in the fetch. The experiments were performed with a smooth floor fetch followed by snowpacks that were collected during snowfalls immediately before the experiments. The snow grains were of stellar crystal shape with sizes between 0.5 and $2 \mathrm{~mm}$. In total, four erosion experiments organized in two measurement series with different snowpacks were performed. In each measurement series, two experiments with the same snowpack were performed for constant free-stream velocities $U_{\delta}$ ranging from 9 to $10 \mathrm{~m} \mathrm{~s}^{-1}$ (hereafter referred to as exp. 1a, exp. 1b and exp. 2a, exp. 2b). These velocities guaranteed snow transport with distinct saltation throughout the experiments. The total depletion of snow by erosion in the measurement section was $<5 \mathrm{~mm}$ within each measurement series. The air temperature in the boundary-layer wind tunnel during the first and second measurement series was fairly constant at $-1.4 \pm 0.1^{\circ} \mathrm{C}$ and $-4.5 \pm 0.2^{\circ} \mathrm{C}$, respectively. The boundary conditions of the experiments are summarized in Table 1.

\subsection{Measurement technique}

Shadowgraphy was applied to study snow particle size characteristics. The shadowgraphy system consisted of a diffuse-area light source and a complementary metal oxide semiconductor (CMOS) camera (LaVision, 2010) positioned on opposite wind-tunnel side-walls (Fig. 1). The CMOS camera recorded shadow images of the snow particles passing the illuminated volume with an aperture exposure time of $0.0001 \mathrm{~s}$ and a frame rate of $50 \mathrm{~Hz}$. Image recording was controlled in the DaVis 8 hardware and software environment (LaVision, 2011a). The camera focal plane was located at the centre axis of the wind tunnel with a field of view of approximately $50 \mathrm{~mm} \times 50 \mathrm{~mm}$ in the first measurement series and $25 \mathrm{~mm} \times 50 \mathrm{~mm}$ (horizontal $\times$ vertical) in the second. With a CMOS chip consisting of $1024 \times 1024$ pixels, this resulted in a resolution of 20 pixels $\mathrm{mm}^{-1}$, i.e. the smallest resolved snow particle diameter is $\sim 0.05 \mathrm{~mm}$. Notice that the focal plane depth is not of interest for this study as long as it is multiple times larger than the saltating snow particle sizes and a depth-of-field (DoF) correction (see Section 2.3) is applied.

The optic system was checked for angular distortion effects. To this end, a transparent scale was positioned in the focal plane and photographed. An analysis of the scale bar 

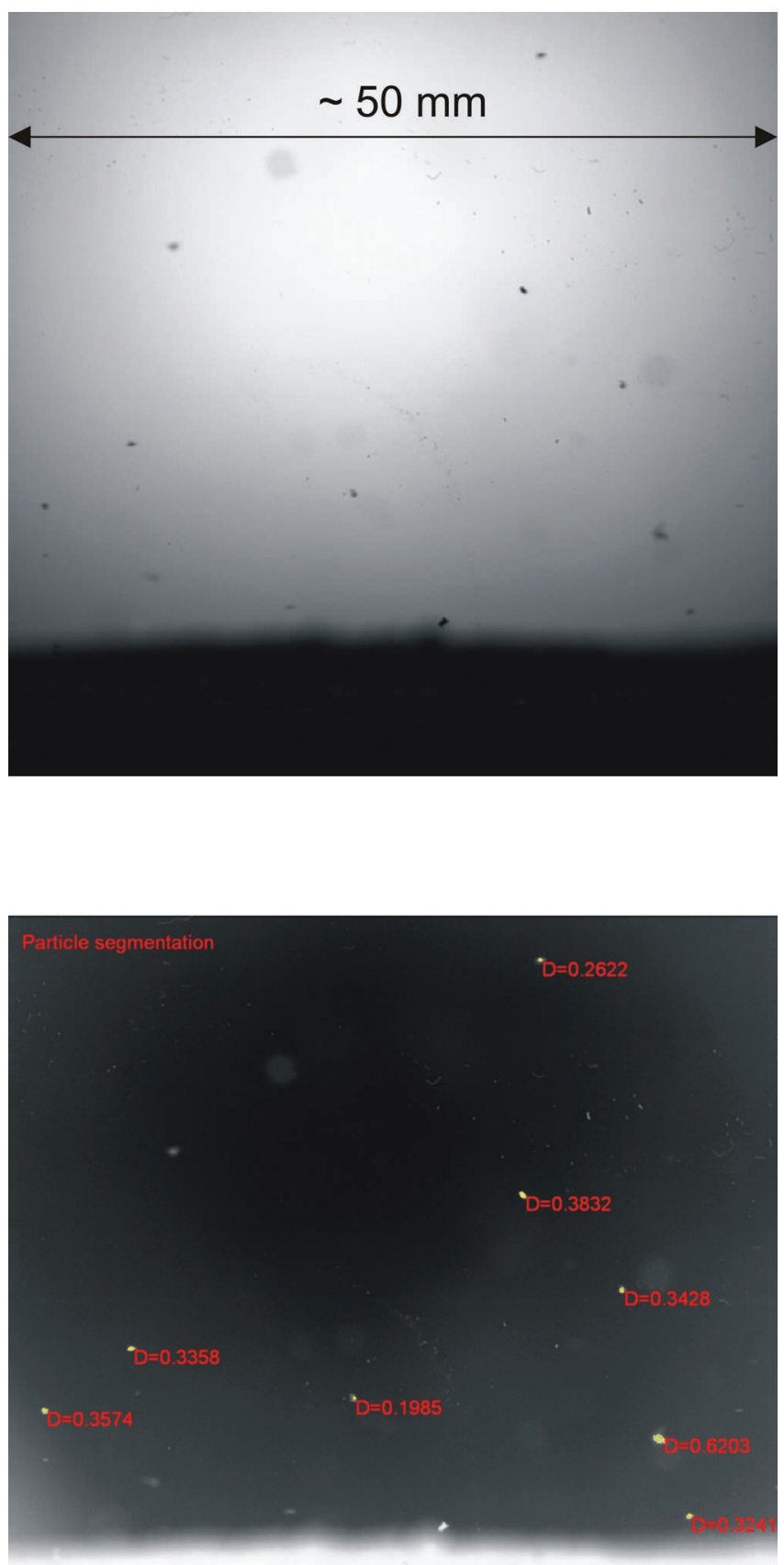

Fig. 2. Shadowgraphy raw image (top), and processed and evaluated image (bottom).

spacing in the centre and at the border of the picture revealed no measurable differences. Thus, possible distortion effects introduced by the optics were considered to be insignificantly small.

To capture the entire saltation layer with an estimated height of $100 \mathrm{~mm}$ by the given field of view with $50 \mathrm{~mm}$ vertical extent, the camera was shifted along a vertical traverse and fixed at three different positions for recording. The positions were chosen such that there was always an overlap among the recording sequences. During the first experiment of the first measurement series (exp. 1a), 1500 frames per sequence (camera position) were recorded, giving a measurement time of $30 \mathrm{~s}$ each. Since the saltation activity, i.e. the number of particles in saltation, was reduced following the erosion of the upper freshest and relatively unbounded snow layer, 3000 frames per sequence $(60 \mathrm{~s})$ were recorded in the second experiment of this series (exp. $1 \mathrm{~b})$. For the second measurement series, 6000 frames per sequence $(120 \mathrm{~s})$ were recorded during the first and second experiments exp. 2a and exp. 2b. The measurement parameters of the experiments are summarized in Table 1. The decrease in snow surface level during erosion was accounted for in the subsequent evaluation by linearly distributing the snow surface height difference between the first and last images of a recoding sequence.

\subsection{Image processing and evaluation}

Figure 2 shows a recorded raw shadow image (top) and the processed and evaluated image (bottom) of saltating snow particles just above the snow surface. Only snow particles that appear sufficiently sharp and dark are recognized and contribute to the particle size statistics. These particles are in their focal plane, whose depth in the present experimental set-up with the diffuse-area light source scales linearly with the particle size itself. This means that smaller particles are underrepresented relative to larger particles. In order to remove this bias, a DoF correction (Kim and Kim, 1994) was applied on particle size classes in a subsequent MATLAB evaluation upon the image processing and basic evaluation described in the following paragraphs. In the DoF correction the number of particles of each size class was multiplied by a correction factor, which is the ratio of an arbitrary reference size class diameter to the size class diameter under consideration. In this way, corrected numbers of snow particles per size class were obtained. It is noted that the DoF correction performed here did not serve the purpose of determining the actual depth of the focal plane as a function of particle size. The actual depths, which remained undetermined, and the arbitrary reference size class diameter were not relevant for the particle size analyses presented in this study. However, the actual focal plane depths are required for concentrations of snow particle number or mass, or for mass flux analyses.

The image processing and basic evaluation was performed in the software environment DaVis 8 (LaVision, 2011b). The fundamental steps together with recommendations for the choice of parameter settings required in the image processing and evaluation are described in the supplier's shadowgraphy manual (LaVision, 2011c). The parameter settings comprise filter types and attributes, threshold values or bounds of image substructure attributes for particle recognition and particle-sizing algorithms. However, to a certain degree the final results are sensitive to the chosen parameter settings in the image processing and evaluation steps. To assess their impact on the final results, the parameter settings were systematically varied and the influence is described below.

For the sensitivity analysis, a total of 12 different evaluation runs were performed on the first sequence (lowest camera position) of exp. 1a. To begin with, a probe sensitivity analysis was carried out to determine parameter settings producing the strongest variability in the results. The following parameter settings were varied:

the radius of the filter kernel for the background light calculation $(45,60,75$ pixels $)$,

the threshold level of pixel intensity to be considered as part of a particle $(40 \%, 50 \%, 60 \%)$, 


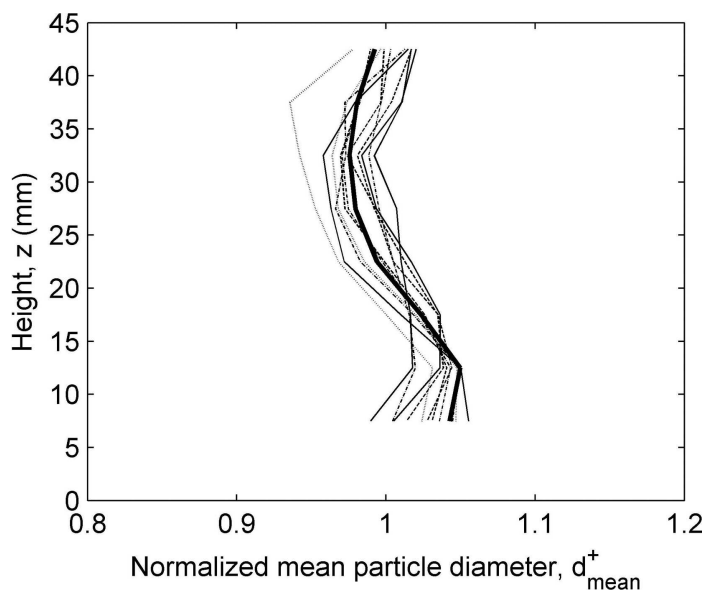

Fig. 3. Normalized mean particle diameter $d_{\text {mean }}^{+}$with height $z$. The parameter settings leading to the thicker solid line were employed for the analysis.

the low and high pixel-intensity levels for the determination of particle properties such as diameter and centricity (30/70\%, 40/60\%, 50/50\%).

Notice that the chosen options and settings are partly software-specific, and their transfer to other image-processing and evaluation environments may not always be straightforward. However, to maintain transparency the variations in the parameter settings are explicitly given here.

Figure 3 shows the variation of the normalized mean diameter $d_{\text {mean }}^{+}$with height above the snow surface as obtained from the 12 evaluation runs. The mean diameters were normalized with respect to the average mean diameter over all heights and evaluation runs. It can be seen that the different parameter settings did not strongly affect the mean snow particle diameter. In general, the deviation from the average mean particle diameter is $<5 \%$. The absolute variation is of the order of the CMOS chip resolution, i.e. $\sim 0.05 \mathrm{~mm}$.

In contrast, the parameter settings strongly affected the total number of detected snow particles, with almost a factor two difference between the minimum and maximum number of particles. This strong variability is without consequence for the analysis of snow particle size characteristics and their height profiles; however, it affects the outcomes in terms of absolute particle number and thus concentration of snow particle number and mass, as well as mass flux.

Based on the sensitivity analysis, the following parameter settings for the image processing and evaluation were chosen: 45 pixels for the radius of the filter kernel for the background light calculation, 50\% for the threshold level of pixel intensity to be considered as part of a particle, and $40 / 60 \%$ for the low and high pixel-intensity levels for the determination of particle properties. The mean particle diameters obtained with these settings are indicated in Figure 3 by the thicker solid line which lies fairly well centred within the line ensemble.

\section{RESULTS AND DISCUSSION}

\subsection{Snow particle number}

From the recordings, the first $100 \mathrm{~mm}$ above the snow surface accommodating the saltation layer was analysed.

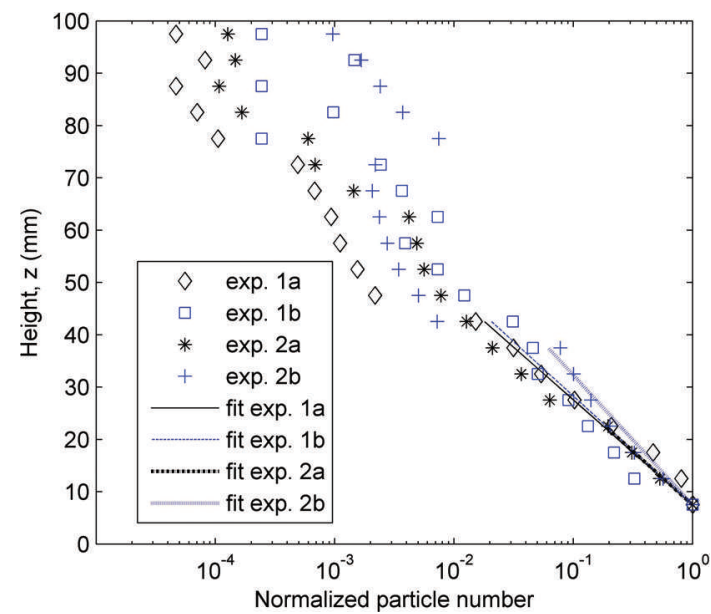

Fig. 4. Normalized particle number variation with height $z$.

This area was subdivided into 20 height-level intervals of $5 \mathrm{~mm}$. The lowest height level $(0-5 \mathrm{~mm})$ was excluded from the analysis since it was covered by the snow surface behind the focal plane on the images (Fig. 2).

Figure 4 shows the particle number per height level normalized by the maximum particle number in the 5-10 mm height level (lowest evaluated height level). It can be seen that the particle number decreases rapidly with height and seems to follow an exponential relation. At a height of $\sim 45 \mathrm{~mm}$, the particle number is reduced to $\sim 1-3 \%$ of that at the near-surface $5-10 \mathrm{~mm}$ height level. The larger scatter in the upper height levels $(z>75 \mathrm{~mm})$ is due to the small numbers of particles detected, which do not provide a sufficiently large database. The discontinuities in the particle number between height levels $35-50 \mathrm{~mm}$ and $70-85 \mathrm{~mm}$ are due to the different saltation activities during the recording sequences. Because of less sintering of the fresher grains at the top of the snowpack, the saltation activity was relatively strong at the beginning of a measurement series and decreased in the course of an experiment. In particular during the first experiment (exp. 1a) a much stronger saltation activity was observed initially while the upper freshest and relatively unbounded snow layer was being eroded. This is reflected in the abrupt decrease in particle number between height levels $40-45$ and $45-50 \mathrm{~mm}$ and limits a direct comparison of the particle numbers resulting from the temporally separated sequences. To this end, only the data of the first recording sequence $(z<45 \mathrm{~mm})$ from each experiment were employed to characterize the snow particle number variation with height according to

$$
n^{+}(z)=\frac{n(z)}{n\left(z_{\text {ref }}\right)}=\exp \left[-\lambda\left(\frac{z}{z_{\text {ref }}}-1\right)\right]
$$

where $n^{+}(z)$ is the normalized particle number at height $z$, $n(z)$ is the particle number at height $z_{1}$ and $z_{\text {ref }}$ is the reference height (here the centre of the lowest available height level, i.e. $z_{\text {ref }}=7.5 \mathrm{~mm}$ ). The exponential decay parameters $\lambda$ and the coefficients of determination $R^{2}$ were determined by regression analyses as $\left(\lambda, R^{2}\right)=(0.86,0.98)$, $(0.83,0.90),(0.84,0.99)$ and $(0.70,0.97)$ for exp. 1a, exp. $1 \mathrm{~b}$, exp. $2 \mathrm{a}$ and exp. $2 \mathrm{~b}$, respectively. The corresponding bounds of the $95 \%$ confidence intervals were for $\lambda=(0.79$, $0.92),(0.72,0.94),(0.77,0.92),(0.63,0.76)$ and for $R^{2}=(0.89,1.00),(0.55,0.98),(0.72,1.00)$ and $(0.81$, 
0.99). Figure 4 shows the resulting profiles according to Eqn (1). These $\lambda$ values are specific to the present experiment boundary conditions; in particular they depend on the chosen reference height $z_{\text {ref }}$. However, they indicate the range in which the decay parameter may be expected to lie. Moreover, the similar values obtained for the first measurement series suggest that the decay parameter $\lambda$ does not strongly depend on the saltation activity, which was very different for exp. 1a and exp. 1b, where a factor of 59 in the number of detected particles during the first recording sequences, i.e. at the lowest camera position, was found.

The observation of exponentially decreasing particle numbers with height is supported by the wind tunnel experiments of Nishimura and Hunt (2000). Guala and others (2008) however, fit their observed decrease in particle number with height using a power law.

\subsection{Snow particle size characteristics}

The snow particle size variations with height for exp. 1a and exp. 2a are shown in Figure $5 \mathrm{a}$ and b, respectively. Since the exponential decrease of particles with height results in very few particles at the upper height levels and inhibits reliable particle size statistics, the analysis was restricted to maximum heights, $h_{\text {stat }}$ of 75, 55, 80 and $100 \mathrm{~mm}$ for exp. $1 \mathrm{a}$, exp. $1 \mathrm{~b}$, exp. $2 \mathrm{a}$ and exp. $2 \mathrm{~b}$, respectively, for which a minimum of 30 particles in the uppermost height level was available.

Both panels clearly show that the mean snow particle diameter is fairly constant below $h_{\text {stat, }}$ with a very slight tendency to decrease with height. This is also valid for the standard deviation of the particle diameter. In contrast, the maximum snow particle diameter decreases roughly linearly with height. At the lowest height levels, it is multiple times $(\sim 5-7)$ larger than the mean diameter. The particle size variations for exp. $1 \mathrm{~b}$ and exp. $2 \mathrm{~b}$ exhibit the same characteristics (not shown here). Nishimura and others (1998) and Sugiura and others (1998), both using a SPC (Sato and others, 1993), report an increase in the share of small particles over height within the saltation layer. The data of Sugiura and others (1998) show a less pronounced increase in the share of small particles at lower heights for larger free stream and friction velocities. Thus, the question arises whether the phenomenon of an increasing share of small particles with height is a characteristic of the saltation layer or of the suspension layer which blend into each other. However, their results imply a decrease of the mean snow particle diameter with height, whereas our results indicate a fairly constant mean particle diameter with only a slight tendency to decrease with height. This may be due to the resolution of the CMOS chip $(0.05 \mathrm{~mm})$ in combination with the image processing and evaluation which does not allow resolution of the smallest particle sizes in such detail as the SPC, and to the different snow particle characteristics in the experiments (1-year-old snow blocks disintegrated into individual particles of mean diameter $0.36 \mathrm{~mm}$ in Sugiura and others' experiments, and snow a couple of hours old, of stellar crystal shape and $0.5-2.0 \mathrm{~mm}$ in diameter in our experiments).

The mean snow particle diameters below $h_{\text {stat }}$ are 0.38 , $0.34,0.35$ and $0.34 \mathrm{~mm}$ for exp. 1a, exp. 1b, exp. 2a and exp. 2b, respectively, and the corresponding standard deviations are $0.16-0.18 \mathrm{~mm}$, i.e. $\sim 50 \%$ of the mean diameter. The values of the mean and maximum diameters are, of course, specific to the boundary conditions before and during the experiments. Different snowpack characteristics, atmospheric and topographic conditions (age of snow,
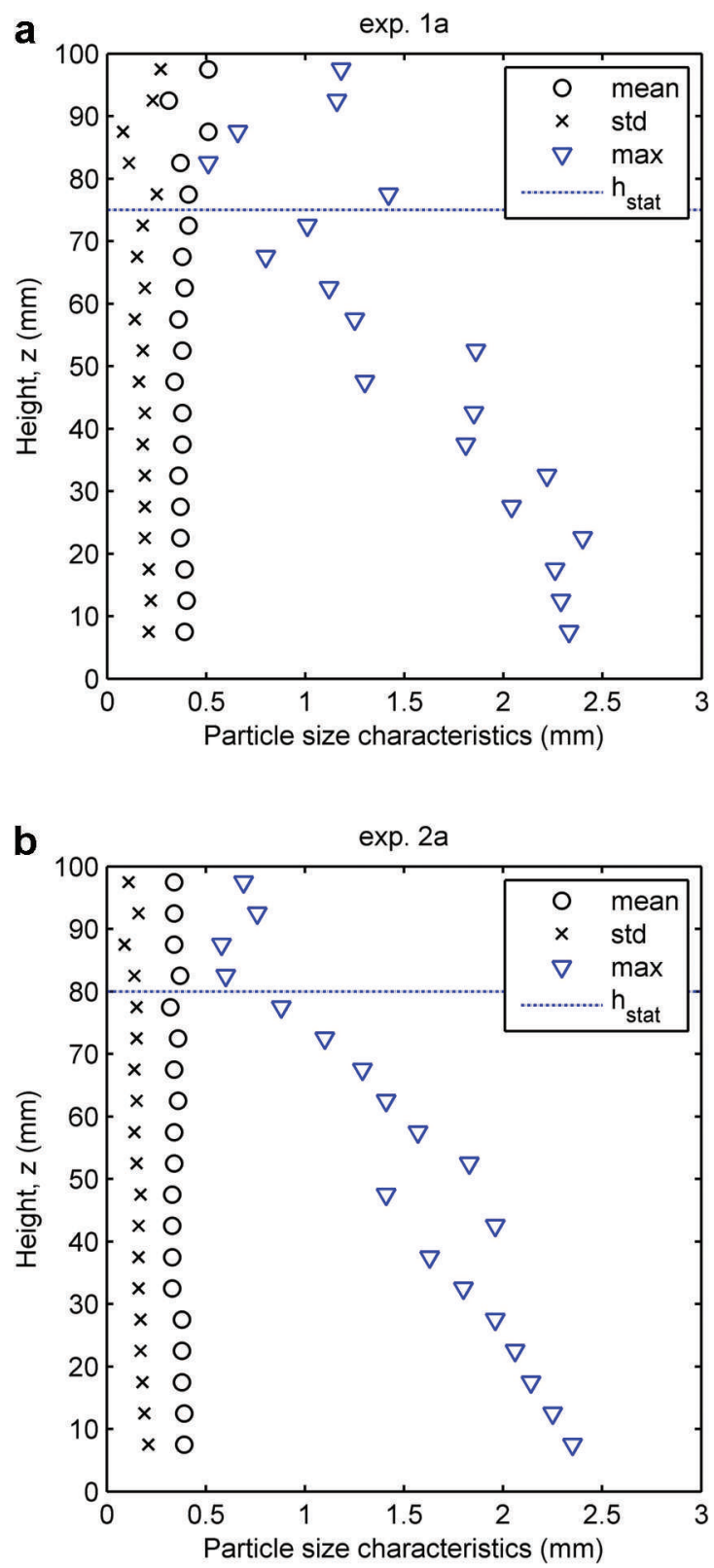

Fig. 5. Particle size characteristics with height $z$ for (a) exp. 1a and (b) exp. 2 a.

crystal form and size, air temperature, wind speed and saltation fetch length) will result in different mean diameters, standard deviations and maximum diameters of saltating snow particles. In particular, the length of the saltation fetch and therefore the average number of snow particle rebounds are hypothesized to influence snow particle size. The mean and maximum diameter will decrease with increasing number of rebounds since particles fracture, in particular during their first impacts and rebounds as long as they are of dendritic shape. Schmidt (1982) measured a mean snow particle diameter of $0.18 \mathrm{~mm}$ at a height of $50 \mathrm{~mm}$ at a field site at 2360 ma.s.I. in southeast Wyoming, USA. From their wind tunnel experiments, Clifton and Lehning (2008) reported mean particle diameters of $0.10-0.30 \mathrm{~mm}$ for fresh saltating snow. Gordon and Taylor (2009) observed mean particle diameters of $0.10-0.17 \mathrm{~mm}$ in field experiments at Churchill, Manitoba, Canada, and Nishimura and Nemoto (2005) measured particle diameters of $0.10-0.23 \mathrm{~mm}$ in a saltation cloud at Mizuho station, Antarctica. The larger 


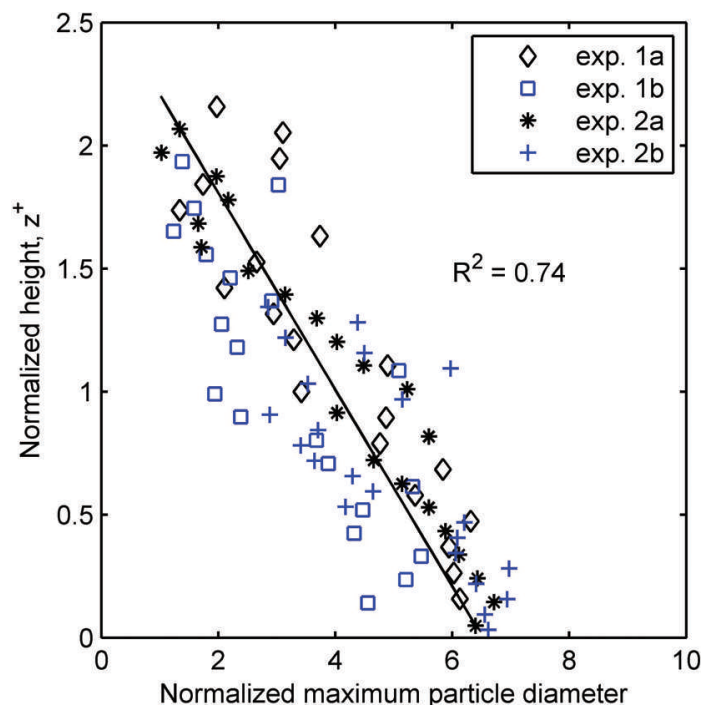

Fig. 6. Normalized maximum particle diameter variation with normalized height $z^{+}$.

mean diameters measured in this study are, among others, attributed to the relatively short saltation fetch in the boundary-layer wind tunnel $(7 \mathrm{~m})$ and the smaller number of rebounds and hence less particle fracture before passing the measurement location.

Figure 6 shows the normalized maximum particle diameter with height for all experiments. The maximum particle diameter is normalized by the mean diameter, and the height is normalized by $h_{\text {ref }}$ where the saltation activity expressed by the number of particles is decreased to $1 \%$ of that at the lowest height level (Fig. 4, bottom). The collapse of the data points to a straight line motivates the formulation of a linear relationship according to

$$
d_{\max }^{+}(z)=\frac{d_{\max }(z)}{d_{\text {mean }}}=a_{1}-a_{2} \frac{z}{h_{\text {ref }}}=a_{1}-a_{2} z^{+},
$$

where $d_{\max }^{+}(z)$ is the normalized maximum particle diameter at height $z, d_{\max }(z)$ is the maximum particle diameter at height $z, d_{\text {mean }}$ is the mean particle diameter below $\mathrm{h}_{\text {stat }}, z^{+}$ is the normalized height, and $a_{1}$ and $a_{2}$ are coefficients. A least-squares fit resulted in $a_{1}=6.53(6.15,6.90), a_{2}=2.50$ $(2.18,2.83)$ and a coefficient of determination $R^{2}=0.74$

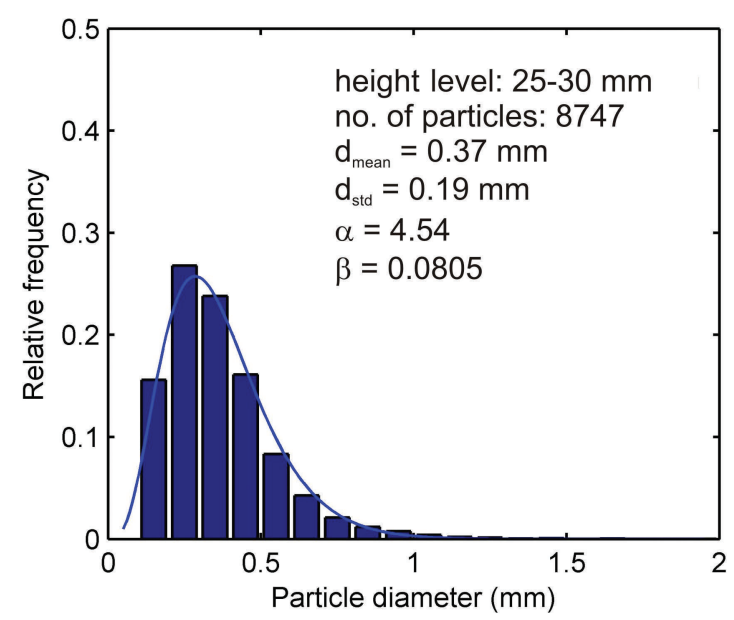

Fig. 7. Snow particle diameter distribution at height level 25-30 $\mathrm{mm}$ and fitted gamma distribution.

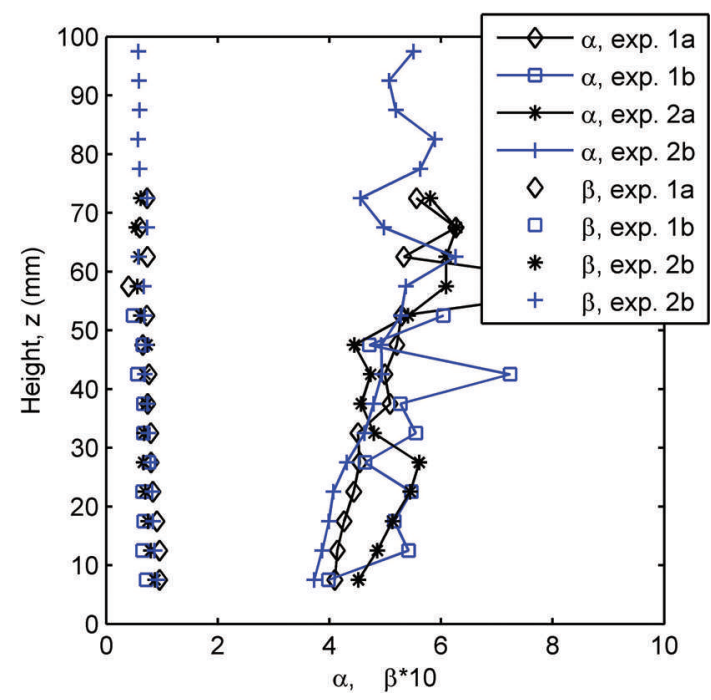

Fig. 8. Vertical variation of shape parameter $\alpha$ and scale parameter $\beta$ of the gamma probability density function.

$(0.63,0.82)$, with the values in parentheses indicating the bounds of the $95 \%$ confidence intervals. However, the decrease of the maximum particle diameter and therefore the decrease of the size of the largest particles do not translate into a reduction of the mean particle diameter with height, due to their relatively low frequency.

\subsection{Snow particle diameter distribution}

Finally, the snow particle size distribution was analysed. For each height level, the snow particle sizes were sorted into size classes of $0.1 \mathrm{~mm}$ bin size, and various statistical distributions were fitted. It was found that the two-parameter gamma probability density function according to

$$
\operatorname{pdf}(\mathrm{d})=\frac{1}{\beta^{\alpha} \Gamma(\alpha)} d^{\alpha-1} \exp \left(-\frac{d}{\beta}\right)
$$

adequately fits the measured snow particle size distribution of every height level in the saltation layer. Here $d$ is the particle diameter, $\alpha$ is the shape parameter, $\beta$ is the scale parameter (with the property $d_{\text {mean }}=\alpha \beta$ ) and $\Gamma$ is the gamma function. Gamma probability distributions were also employed in previous studies to fit snow particle size distributions of drifting and blowing snow (e.g. Schmidt, 1982; Nishimura and Nemoto, 2005; Gordon and Taylor, 2009). Figure 7 shows, as an example, the snow particle size distribution at the $25-30 \mathrm{~mm}$ height level measured during exp. 1a together with the fitted gamma distribution.

The variation of the shape and scale parameter with height is shown in Figure 8. Notice that the scale parameter $\beta$ as displayed in the diagram is multiplied by a factor 10 . The shape parameter $\alpha$ shows a general tendency to increase with height, and the scale parameter $\beta$ shows a weak tendency to decrease with height. The stronger scatter of both parameters at the upper height levels is due to the relatively small number of snow particles, as discussed above. This prevents a reliable estimation of the parameters of the gamma probability density function. Table 2 summarizes the mean values and standard deviations of the shape and scale parameter for the height levels below $40 \mathrm{~mm}$ where a sufficiently large number of particles was present (Fig. 4). 
Table 2. Mean values and standard deviations of the shape $(\alpha)$ and scale $(\beta)$ parameters for height levels below $40 \mathrm{~mm}$

\begin{tabular}{lllll}
\hline & $\alpha_{\text {mean }}$ & $\alpha_{\text {std }}$ & $\beta_{\text {mean }}$ & $\beta_{\text {std }}$ \\
\hline exp. 1a & 4.44 & 0.33 & 0.0860 & 0.0084 \\
exp. 1b & 5.07 & 0.57 & 0.0686 & 0.0041 \\
exp. 2a & 4.99 & 0.42 & 0.0743 & 0.0073 \\
exp. 2b & 4.20 & 0.40 & 0.0819 & 0.0063 \\
\hline
\end{tabular}

Figure 9a and b illustrate the gamma probability density functions for height levels below $30 \mathrm{~mm}$ for the first and second measurement series, respectively. Excluding the outlier from exp. 1 b, i.e. the uppermost dashed curve, the variation in the peak relative frequency (i.e. the frequency of the mode) within each ensemble is in the range $25 \pm 3 \%$, and the curves of each ensemble lie close together. In general, the overall variation within one ensemble is smaller for the second experiment of each measurement series, i.e. for exp. $1 \mathrm{~b}$ and exp. 2b. However, some differences between the experiments can be noticed. Comparing the experiments from the first measurement series, it is evident that the ensemble of distribution functions from exp. $1 \mathrm{~b}$ is characterized by higher peak relative frequencies (higher kurtosis) and smaller fractions at the positive tail (lower skewness) than that from exp. 1a, and the modes tend to be shifted towards slightly smaller diameters. For the second measurement series (exp. 2), the ensemble of distribution functions from exp. $2 b$ is clearly shifted to lower mean diameters and exhibits a smaller variability in the peak relative frequency than that from exp. 2a. These systematic variations are attributed to different snowpack characteristics, with smaller particle sizes in the second compared to the first experiment where the fresher and larger snow particles of the top layer have been eroded away. Apparently, this effect dominates over the influence of the higher wind speed in the second experiment, which is expected to pick up large particles (Nishimura and Nemoto, 2005). However, the present database does not allow profound relationships to be established between these variables, or final conclusions to be drawn, since only four experiments with rather similar free-stream velocities $\left(U_{\delta}=9.0-10.0 \mathrm{~m} \mathrm{~s}^{-1}\right)$ were performed and the snowpack variability between the experiments was not studied. The insets in Figure 9a and b show close-ups of the gamma probability density functions for the four height levels between 10 and $30 \mathrm{~mm}$ in the range of the largest snow particles for exp. 1a and exp. 1b. It can clearly be seen that the relative frequency of the largest particles decreases with increasing height level.

As mentioned above, gamma probability density functions have also been used by other authors (e.g. Schmidt, 1982, 1986; Nishimura and Nemoto, 2005; Gordon and Taylor, 2009) to describe the snow particle size distributions of drifting snow in field studies. They have been applied to snow particle size distributions in the first few meters above the surface and outside the saltation layer. Compared to the wind tunnel measurements presented herein, these studies generally report lower values for the shape and scale parameters $\alpha$ and $\beta$. However, this does not contradict the findings of this study, since the mean particle diameter of drifting snow decreases with height above the saltation layer (e.g. Schmidt, 1982; Nemoto and Nishimura, 2004) and with the drifting-snow fetch, which was relatively short in
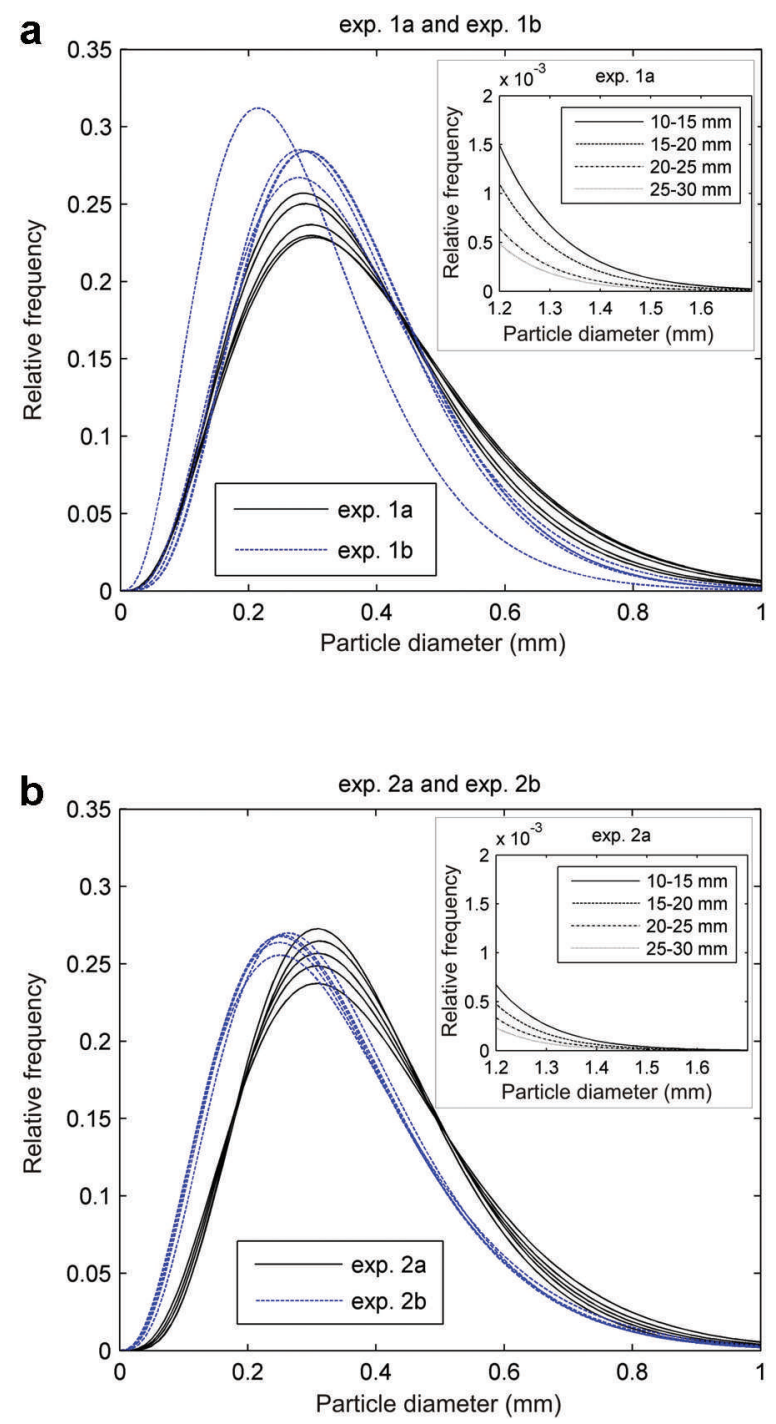

Fig. 9. Gamma probability density functions of the height levels below $30 \mathrm{~mm}$ for the first (a) and second (b) measurement series.

our study, as discussed above. To the best of our knowledge, values of the shape parameter $\alpha$ in the saltation layer are only provided by Nishimura and Nemoto (2005) and Gordon and Taylor (2009). The former report values of $\alpha$ of $\sim 3$ for friction velocities $u_{*}=0.28-0.56 \mathrm{~m} \mathrm{~s}^{-1}$ and $\sim 5$ for $u_{*}=0.21 \mathrm{~m} \mathrm{~s}^{-1}$ from field measurements at Mizuho station, whereas the latter found values for $\alpha$ of 1.4 and 2.25 in field measurements at Churchill. The discrepancy with this study may be attributed not only to different snowpack characteristics, but also to the presence of a much longer fetch in the field and a larger number of particle rebounds, which resulted in different snow particle size characteristics. In particular, the smaller shape parameters, $\alpha$, found in the field studies are attributed to the larger number of rebounds whereby the fragile dendritic arms of the snow crystals break away and rather spherical or ellipsoidal ice cores remain, with a narrower size distribution.

\section{SUMMARY AND CONCLUSION}

Snow particle size characteristics in the saltation layer were investigated with shadowgraphy in wind tunnel experiments. Vertical profiles of particle number, particle size characteristics and particle diameter distribution were studied. 
The snow particle number was found to decrease exponentially with height, and a functional relationship is provided by Eqn (1). The quantitative decrease was similar for all experiments performed in this study, with exponential decay parameters in the range $0.70-0.86$. The decay parameter was found not to depend strongly on the saltation activity (number of particles in saltation).

A fairly height-independent mean snow particle diameter in the saltation layer was observed. Mean diameters of 0.38 and $0.34 \mathrm{~mm}$ in exp. $1 \mathrm{a}$ and exp. $1 \mathrm{~b}$, and 0.35 and $0.34 \mathrm{~mm}$ in exp. 2a and exp. $2 b$ were measured. The smaller mean particle diameter in the second experiment of each measurement series was attributed to the rapid erosion of the upper freshest and unbounded snow grains during the first saltation experiment. It is acknowledged that these values are specific to the snowpack and boundary conditions of the experiments performed. However, the fundamental observations of a fairly constant mean and a linearly with height decreasing maximum snow particle diameter in the saltation layer may be universally valid, and remain to be substantiated by further studies. With Eqn (2), a universal functional relationship between the maximum particle diameter and the mean particle diameter as a function of height is suggested.

The particle size distributions could be adequately described by gamma probability density functions. Thus, the distribution type found in blowing-snow investigations elsewhere also applies for the saltation layer. While the shape parameter showed an increase with height, the scale parameter tended to decrease with height. Moreover, some characteristic differences across the experiments of each measurement series were found, indicating a dependency on the snowpack and experiment boundary conditions. However, the number of experiments performed is too small to provide final conclusions.

The influence of the image processing and evaluation settings on the outcomes was analysed. Based on the analysis, the mean particle diameter provided was found to be subject to variations of $<5 \%$ (Fig. 2), which is considered low. This suggests shadowgraphy is a robust method for studying particle size characteristics of drifting and blowing snow or, more generally, for studying aeolian sediment transport. A limitation in this study was that saltation close to the surface $(<5 \mathrm{~mm})$ could not be studied. This is, however, not a general limitation of shadowgraphy and can be fixed by positioning the camera such that the centre of the image is levelled with the surface of the erodible ground.

In comparison to conventional snow particle counters (SPCs), shadowgraphy is a volume measurement method rather than a point measurement method. The simultaneous and highly time-resolved measurement of a larger area enables the study of hitherto unexplored drifting- and blowing-snow characteristics (e.g. the exploration of coherent structures or characteristics in the particle phase). It also allows detection of larger snow particles than SPCs, whose upper limit is $\sim 0.5 \mathrm{~mm}$. Shadowgraphy is a promising method for future investigations of aeolian sediment transport.

\section{ACKNOWLEDGEMENTS}

We thank the Swiss National Science Foundation (SNF) for the measurement equipment grant ( $R^{\prime}$ Equip grant No. 206021_133786), and the SLF workshop for support with installing the measurement equipment.

\section{REFERENCES}

Chritin V, Bolognesi R and Gubler H (1999) FlowCapt: a new acoustic sensor to measure snowdrift and wind velocity for avalanche forecasting. Cold Reg. Sci. Technol., 30(1-3), 125-133 (doi: 10.1016/S0165-232X(99)00012-9)

Cierco F-X, Naaim M and Naaim-Bouvet F (2008) Experimental study of particle concentration fluctuations in a turbulent steady flow. Ann. Glaciol., 49, 121-126 (doi: 10.3189/ 172756408787814780)

Clifton A and Lehning M (2008) Improvement and validation of a snow saltation model using wind tunnel measurements. Earth Surf. Process. Landf., 33(14), 2156-2173 (doi: 10.1002/ esp.1673)

Clifton A, Rüedi JD and Lehning M (2006) Snow saltation threshold measurements in a drifting-snow wind tunnel. J. Glaciol., 52(179), 585-596 (doi: 10.3189/172756506781828430)

Creyssels M and 7 others (2009) Saltating particles in a turbulent boundary layer: experiment and theory. J. Fluid Mech., 625 47-74 (doi: 10.1017/S0022112008005491)

Dong Z, Wang H, Zhang X and Ayrault M (2003) Height profile of particle concentration in an aeolian saltating cloud: a wind tunnel investigation by PIV MSD. Geophys. Res. Lett., 30(19), 2004 (doi: 10.1029/2003GL017915)

Doorschot J and Lehning M (2002) Equilibrium saltation: mass fluxes, aerodynamic entrainment, and dependence on grain properties. Bound.-Layer Meteorol., 104(1), 111-130 (doi: 10.1023/A:1015516420286)

Doorschot J, Raderschall N and Lehning M (2001) Measurements and one-dimensional model calculations of snow transport over a mountain ridge. Ann. Glaciol., 32, 153-158 (doi: 10.3189/ 172756401781819616)

Gauer P (2001) Numerical modeling of blowing and drifting snow in Alpine terrain. J. Glaciol., 47(156), 97-110 (doi: 10.3189/ 172756501781832476)

Gordon M and Taylor PA (2009) Measurements of blowing snow, Part I: particle shape, size distribution, velocity, and number flux at Churchill, Manitoba, Canada. Cold Reg. Sci. Technol., 55(1), 63-74 (doi: 10.1016/j.coldregions. 2008.05.001)

Gordon M, Savelyev S and Taylor PA (2009) Measurements of blowing snow, part II: Mass and number density profiles and saltation height at Franklin Bay, NWT, Canada. Cold Reg. Sci. Technol., 55(1), 75-85 (doi: 10.1016/j.coldregions.2008. 07.001)

Greeley R and Iversen JD (1985) Wind as a geological process on Earth, Mars, Venus and Titan. Cambridge University Press, Cambridge

Gromke C and Burri K (2011) Wind erosion. In Gliésky J, Horabik J and Lipiec J eds. Encyclopedia of agrophysics. Springer, Dordrecht, 997-1000

Gromke C, Manes C, Walter B, Lehning M and Guala M (2011) Aerodynamic roughness length of fresh snow. Bound.-Layer Meteorol., 141(1), 21-34 (doi: 10.1007/s10546-011-9623-3)

Guala M, Manes C, Cliton A and Lehning M (2008) On the saltation of fresh snow in a wind tunnel: profile characterization and single particle statistics. J. Geophys. Res., 113(F3), F03024 (doi: 10.1029/2007JF000975)

Kim KS and Kim S-S (1994) Drop sizing and depth-of-field correction in TV imaging. Atomiz. Sprays, 4(1), 65-78

Kind RJ (1990) Mechanics of aeolian transport of snow and sand. J. Wind Eng. Ind. Aerodyn., 36(2), 855-866 (doi: 10.1016/01676105(90)90426-D)

LaVision (2010) Product-manual HighSpeedStar 5. LaVision, Goettingen

LaVision (2011a) Product-manual Imaging Tools. LaVision, Goettingen

LaVision (2011b) Product-manual DaVis 8.0 software. LaVision, Goettingen

LaVision (2011c) Product-manual ParticleMaster Shadow. LaVision, Goettingen 
Liston GE and Sturm M (1998) A snow-transport model for complex terrain. J. Glaciol., 44(148), 498-516

Naaim-Bouvet F, Bellot H and Naaim M (2010) Back analysis of drifting-snow measurements over an instrumented mountainous site. Ann. Glaciol., 51(54), 207-217 (doi: 10.3189/ 172756410791386661)

Nemoto M and Nishimura K (2004) Numerical simulation of snow saltation and suspension in a turbulent boundary layer. J. Geophys. Res., 109(D18), D18206 (doi: 10.1029/ 2004JD004657)

Nishimura K and Hunt JCR (2000) Saltation and incipient suspension above a flat particle bed below a turbulent boundary layer. J. Fluid Mech., 417, 77-102 (doi: 10.1017/ S0022112000001014)

Nishimura $K$ and Nemoto M (2005) Blowing snow at Mizuho station, Antarctica. Philos. Trans. R. Soc. London, Ser. A, 363(1832), 1647-1662 (doi: 10.1098/rsta.2005.1599)

Nishimura K, Sugiura K, Nemoto M and Maeno N (1998) Measurements and numerical simulations of snow-particle saltation. Ann. Glaciol., 26, 184-190

Pomeroy JW (1989) A process-based model of snowdrifting. Ann. Glaciol., 13, 237-240

Pomeroy JW and Gray DM (1990) Saltation of snow. Water Resour. Res., 26(7), 1583-1594 (doi: 10.1029/WR026i007p01583)
Radok U (1968) Deposition and erosion of snow by the wind. CRREL Res. Rep. 230

Sato T, Kimura T, Ishimaru T and Maruyama T (1993) Field test of a new snow-particle counter (SPC) system. Ann. Glaciol., 18, 149-154

Schmidt RA (1982) Vertical profiles of wind speed, snow concentration and humidity in blowing snow. Bound.-Layer Meteorol., 23(2), 223-246 (doi: 10.1007/BF00123299)

Schmidt RA (1984) Measuring particle size and snowfall intensity in drifting snow. Cold Reg. Sci. Technol., 9(2), 121-129 (doi: 10.1016/0165-232X(84)90004-1)

Schmidt RA (1986) Transport rate of drifting snow and the mean wind speed profile. Bound.-Layer Meteorol., 34(3), 213-241 (doi: 10.1007/BF00122380)

Sugiura K, Nishimura K, Maeno N and Kimura T (1998) Measurements of snow mass flux and transport rate at different particle diameters in drifting snow. Cold Reg. Sci. Technol., 27(2), 83-89 (doi: 10.1016/S0165-232X(98)00002-0)

Takeuchi M (1980) Vertical profile and horizontal increase of driftsnow transport. J. Glaciol., 26(94), 481-492

Xiao J, Bintanja R, Déry SJ, Mann G and Taylor PA (2000) An intercomparison among four models of blowing snow. Bound.-Layer Meteorol., 97(1), 109-135 (doi: 10.1023/ A:1002795531073)

MS received 11 August 2013 and accepted in revised form 27 January 2014 